\title{
Three-Dimensional Failure Criteria Based on the Hoek-Brown Criterion
}

\author{
Stephen Priest
}

Published online: 18 July 2012

(C) Springer-Verlag 2012

\section{List of symbols}

$m_{\mathrm{b}} \quad$ Hoek-Brown material constant

$s \quad$ Hoek-Brown material constant

a Hoek-Brown material constant

$C_{\mathrm{o}} \quad$ Uniaxial compressive strength

$I_{1}^{\prime} \quad$ First invariant of the effective stress tensor

$\sigma_{1}^{\prime} \quad$ Major principal effective stress

$\sigma_{2}^{\prime} \quad$ Intermediate principal effective stress

$\sigma_{3}^{\prime} \quad$ Minor principal effective stress

$\tau_{\text {oct }}$ Octahedral shear stress

$\sigma_{1 \mathrm{hb}}^{\prime} \quad$ Major principal effective stress at failure for the 2D

Hoek-Brown criterion

$\sigma_{3 \mathrm{hb}}^{\prime} \quad$ Minor principal effective stress at failure for the 2D

Hoek-Brown criterion

$\alpha \quad$ Simplified Priest material constant

$\beta \quad$ Simplified Priest material constant

$w \quad$ Simplified Priest material constant

\section{Description}

There is a growing body of experimental evidence (Takahashi and Koide 1989) to suggest that the intermediate principal stress has a substantial influence on the strength of rock materials. Widely adopted failure criteria, such as the Coulomb and Hoek-Brown criteria, ignore the influence of the intermediate principal stress and therefore may not provide a reliable prediction of rock strength under

S. Priest $(\square)$

School of Civil, Environmental and Mining Engineering,

The University of Adelaide, Adelaide, SA, Australia

e-mail: stephen.priest@adelaide.edu.au true triaxial stress conditions. Although a number of threedimensional failure criteria have been developed, such as the Drucker and Prager (1952) criterion and Lade criterion (Kim and Lade 1984), these criteria were not primarily developed for the application to rocks.

The widespread adoption of the empirical two-dimensional Hoek-Brown failure criterion (2DHB) (Hoek and Brown 1997; Hoek et al. 2002) for rock engineering applications has prompted a number of researchers to develop three-dimensional versions, in which the predicted major effective principal stress at failure is dependent on the intermediate effective principal stress, in addition to the parameters in the existing 2DHB failure criterion. Threedimensional versions of the 2DHB failure criterion have been proposed by Pan and Hudson (1988), Priest (2005) and Zhang and Zhu (2007). Zhang (2008) presented a generalised version of the Zhang-Zhu criterion. Melkoumian et al. (2009) presented an explicit version of the 'comprehensive' Priest criterion. Conventionally, in the literature, each criterion has been named after the author(s) who first described the criterion; this convention will be adopted here. It is likely that additional new three-dimensional versions of the HoekBrown criterion will be developed over the next few years.

\section{Background}

The most recent generalised version of the 2DHB failure criterion is introduced by Eberhardt and Rahjoo (this volume). This version of the Hoek-Brown criterion is here referred to as 'generalised' because the key parameters $m_{\mathrm{b}}$, $s$ and $a$ can take any general values to allow the application to intact rock and to rock masses. The paper explains how the parameters $m_{\mathrm{b}}, s$ and $a$ for a fractured rock mass can be estimated from empirical expressions. 
For intact rock, the parameters $m_{\mathrm{b}}, s$ and $a$ are $m_{\mathrm{i}}, 1.0$ and 0.5 , respectively. A number of authors, including Hoek and Brown (1997), provide tabulations of suggested values of $m_{\mathrm{i}}$ for a range of rock types. Alternatively, the parameters $m_{\mathrm{i}}, s$ and $a$ can be determined from a series of conventional triaxial tests on intact rock, as explained by Eberhardt and Rahjoo (this volume).

In the following section, three-dimensional versions of the Hoek-Brown criterion have been expressed in terms of the parameters $m_{\mathrm{b}}, s$ and $a$, in order to provide a generalised formulation. However, since these criteria have not been shown to be, nor indeed claimed to be, applicable to fractured rock masses, the parameters $m_{\mathrm{b}}, s$ and $a$ should be replaced by $m_{\mathrm{i}}, 1.0$ and 0.5 , respectively, and the criteria limited to the application to intact rock materials.

\section{Formulation}

\subsection{Generalised Zhang-Zhu (GZZ) Criterion}

The Zhang-Zhu criterion was first presented by Zhang and Zhu (2007). A generalised version of this criterion, based on the generalised Hoek-Brown criterion, was presented by Zhang (2008) as follows:

$s C_{\mathrm{o}}=C_{\mathrm{o}}^{\left(1-\frac{1}{a}\right)}\left(\frac{3 \tau_{\mathrm{oct}}}{\sqrt{2}}\right)^{\frac{1}{a}}+\frac{3 m_{\mathrm{b}} \tau_{\mathrm{oct}}}{2 \sqrt{2}}-\frac{m_{\mathrm{b}}\left(3 I_{1}^{\prime}-\sigma_{2}^{\prime}\right)}{2}$

where $\sigma_{3}^{\prime}$ is the minor effective principal stress at failure, $\sigma_{2}^{\prime}$ is the intermediate effective principal stress at failure, $\sigma_{1}^{\prime}$ is the major effective principal stress at failure, and the other Hoek-Brown parameters are as defined earlier.

$\tau_{\mathrm{oct}}=\frac{\sqrt{\left(\sigma_{1}^{\prime}-\sigma_{2}^{\prime}\right)^{2}+\left(\sigma_{2}^{\prime}-\sigma_{3}^{\prime}\right)^{2}+\left(\sigma_{3}^{\prime}-\sigma_{1}^{\prime}\right)^{2}}}{3}$

and $I_{1}^{\prime}$ is given by

$I_{1}^{\prime}=\frac{\sigma_{1}^{\prime}+\sigma_{2}^{\prime}+\sigma_{3}^{\prime}}{3}$

In Eq. (1),

$\frac{m_{\mathrm{b}}\left(3 I_{1}^{\prime}-\sigma_{2}^{\prime}\right)}{2}=\frac{m_{\mathrm{b}}\left(\sigma_{3}^{\prime}+\sigma_{1}^{\prime}\right)}{2}$

Unfortunately, this failure criterion cannot easily be formulated to express $\sigma_{1}^{\prime}$ explicitly in terms of the input data. It is, however, a relatively straightforward matter to apply a numerical strategy to determine the value of $\sigma_{1}^{\prime}$ that satisfies Eqs. (1)-(3).

\subsection{Generalised Pan-Hudson (GPH) Criterion}

Zhang and Zhu (2007) demonstrated that the only difference between their yield criterion and the one proposed by
Pan and Hudson (1988) is the absence of the intermediate principal stress in the third term of Eq. (1). The generalised form of the Pan-Hudson criterion can be written as

$s C_{\mathrm{o}}=C_{\mathrm{o}}^{\left(1-\frac{1}{a}\right)}\left(\frac{3 \tau_{\mathrm{oct}}}{\sqrt{2}}\right)^{\frac{1}{a}}+\frac{3 m_{\mathrm{b}} \tau_{\mathrm{oct}}}{2 \sqrt{2}}-m_{\mathrm{b}} I_{1}^{\prime}$

where the parameters are as defined earlier. Again, a numerical strategy is required to determine the value of $\sigma_{1}^{\prime}$ in Eq. (4). Although there is apparently only a minor difference between the GZZ and GPH criteria, these criteria predict very different strength values.

\subsection{Generalised Priest (GP) Criterion}

A three-dimensional version of the Hoek-Brown yield criterion was developed by Priest (2005) by combining the two-dimensional Hoek and Brown (1997) and the three-dimensional Drucker and Prager (1952) criteria. The nomenclature 'Priest criterion' has been adopted following Zhang (2008). The term 'comprehensive' three-dimensional Hoek-Brown criterion was adopted by Priest (2005) to distinguish this failure criterion from the 'simplified' version described below. The term 'comprehensive' is somewhat misleading, since this criterion is no more comprehensive than the other criteria outlined above. This criterion will therefore be referred to as the generalised Priest criterion (Priest 2009). The formulation presented by Priest (2005) required a numerical solution strategy. Melkoumian et al. (2009) addressed this problem by developing an explicit version of this three-dimensional Hoek-Brown criterion involving the 2DHB minimum effective stress at failure $\sigma_{3 \mathrm{hb}}^{\prime}$, as summarised below:

$$
\begin{aligned}
& C=s+\frac{m_{\mathrm{b}}\left(\sigma_{2}^{\prime}+\sigma_{3}^{\prime}\right)}{2 C_{\mathrm{o}}} \\
& E=2 C^{a} C_{\mathrm{o}} \\
& F=3+2 a C^{a-1} m_{\mathrm{b}}
\end{aligned}
$$

$\sigma_{3 \mathrm{hb}}^{\prime}=\frac{\sigma_{2}^{\prime}+\sigma_{3}^{\prime}}{2}+\frac{-E \pm \sqrt{E^{2}-F\left(\sigma_{2}^{\prime}-\sigma_{3}^{\prime}\right)^{2}}}{2 F}$

Equation (8) gives two values for $\sigma_{3 \mathrm{hb}}^{\prime}$, one of which can be negative and the other positive. In a compressive stress regime, $\sigma_{3 \mathrm{hb}}^{\prime}$ will be positive, so Melkoumian et al. (2009) recommended that the greater or positive root in Eq. (8) should be adopted.

$P=C_{\mathrm{o}}\left\{\left(\frac{m_{\mathrm{b}} \sigma_{3 \mathrm{hb}}^{\prime}}{C_{\mathrm{o}}}\right)+s\right\}^{a}$

Finally,

$\sigma_{1}^{\prime}=3 \sigma_{3 \mathrm{hb}}^{\prime}+P-\left(\sigma_{2}^{\prime}+\sigma_{3}^{\prime}\right)$. 


\subsection{Simplified Priest (SP) Criterion}

Priest (2005) proposed a 'simplified' three-dimensional version of the Hoek-Brown criterion, which has the merit of providing an easily computed estimate for the threedimensional effective failure stress $\sigma_{1}^{\prime}$.

$\sigma_{1}^{\prime}=\sigma_{1 \mathrm{hb}}^{\prime}+2 \sigma_{3 \mathrm{hb}}^{\prime}-\left(\sigma_{2}^{\prime}+\sigma_{3}^{\prime}\right)$

where, as before, $\sigma_{3 \mathrm{hb}}^{\prime}$ is the minimum $2 \mathrm{DHB}$ effective stress at failure, and $\sigma_{1 \mathrm{hb}}^{\prime}$ is the maximum $2 \mathrm{DHB}$ effective stress at failure, calculated from Eq. (2), and

$\sigma_{3 \mathrm{hb}}^{\prime}=w \sigma_{2}^{\prime}+(1-w) \sigma_{3}^{\prime}$

where $w$ is a weighting factor in the range $0-1$, which governs the relative influence of $\sigma_{2}^{\prime}$ and $\sigma_{3}^{\prime}$ on the strength of the rock. Priest (2005) suggested that for a wide range of rock types, $w$ can be estimated from the following simple power law.

$\mathrm{w} \approx \alpha \sigma_{3}^{\prime \beta}$

Preliminary studies by Priest (2005) suggest that, as a first approximation, $\alpha=\beta=0.15$.

\section{Experimental Data on Rock}

True triaxial rock test data published by Chang and Haimson (2000) for the KTB amphibolite and by Haimson and Chang (2000) for Westerly granite were selected to compare the predictions of the four three-dimensional Hoek-Brown failure criteria. Data published in these papers include uniaxial and 'conventional' triaxial test data for these rocks (where $\sigma_{2}^{\prime}=\sigma_{3}^{\prime}$ ), so it was possible to determine the experimental values of the Hoek-Brown parameter $m_{\mathrm{i}}$ and the uniaxial compressive strength of the intact rock material $C_{\mathrm{o}}$, on the assumption that the HoekBrown parameters $s$ and $a$ are 1.0 and 0.5, respectively, for the intact rock specimens. Simple curve fitting against the data presented for these two rock types gave the following best estimates for the key parameters: KTB amphibolite $m_{\mathrm{i}}=35.4, C_{\mathrm{o}}=159.1 \mathrm{MPa}$; Westerly granite $m_{\mathrm{i}}=40.5$, $C_{\mathrm{o}}=191.0 \mathrm{MPa}$. Although the test data can be compared with the predictions of the yield criteria in a number of different ways, including, for example, plots of failure envelopes in the deviatoric plane, the primary focus here will be to examine how well the failure criteria model the influence of the intermediate principal stress $\sigma_{2}^{\prime}$.

Figure 1 shows the four three-dimensional Hoek-Brown failure criteria and also the 2DHB failure criterion for a minor principal effective stress $\sigma_{3}^{\prime}$ of $60 \mathrm{MPa}$ and an intermediate effective principal stress at failure $\sigma_{2}^{\prime}$ ranging from 60 to $450 \mathrm{MPa}$ for KTB amphibolite. This figure

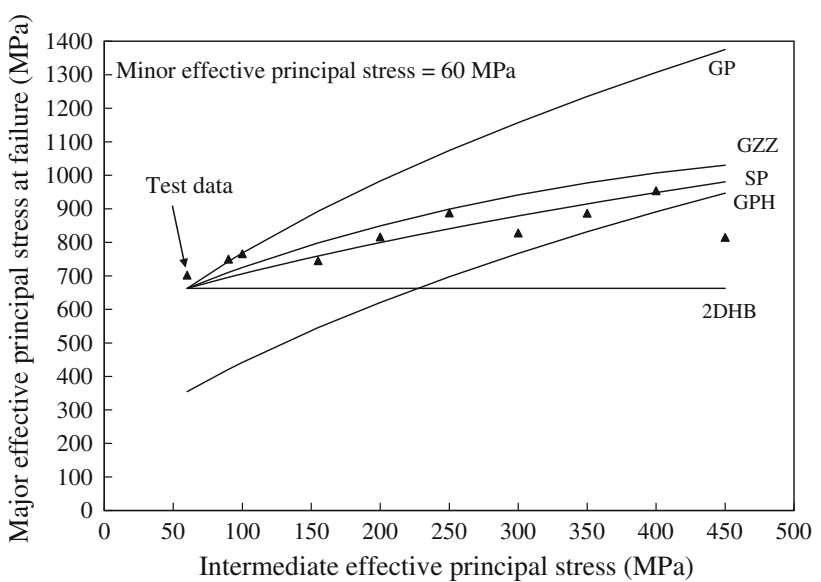

Fig. 1 Four three-dimensional Hoek-Brown failure criteria and also the two-dimensional Hoek-Brown failure criterion for KTB amphibolite, $m_{\mathrm{i}}=35.4, \sigma_{\mathrm{ci}}=159.1 \mathrm{MPa}$

shows that the 2DHB failure criterion is, as expected, insensitive to the intermediate principal stress. All criteria, except the GPH, diverge from the common point where $\sigma_{2}^{\prime}=\sigma_{3}^{\prime}=60 \mathrm{MPa}$ and $\sigma_{1}^{\prime}=662.9 \mathrm{MPa}$. This somewhat anomalous behaviour of the GPH criterion merits further investigation. The generalised Priest criterion (GP) is the most sensitive to the influence of the intermediate principal stress, predicting substantially higher values of $\sigma_{1}^{\prime}$ than the other criteria and the test data. The simplified Priest criterion (SP), adopting Eq. (13) to calculate the weighting factor $w$, is the least sensitive, with the GZZ lying between these two. These latter two criteria appear to model the test data reasonably well. This same general pattern is repeated for the test data at other values of intermediate principal stress, presented by Chang and Haimson (2000), with the simplified Priest (SP) and the GZZ criteria offering the best models for the test data. The test data do, however, indicate that the sensitivity of $\sigma_{1}^{\prime}$ to $\sigma_{2}^{\prime}$ reduces at higher values of $\sigma_{3}^{\prime}$.

Figure 2 shows the four three-dimensional Hoek-Brown failure criteria and also the 2DHB failure criterion for a minor principal effective stress $\sigma_{3}^{\prime}$ of $20 \mathrm{MPa}$ and an intermediate effective principal stress at failure $\sigma_{2}^{\prime}$ ranging from 20 to $202 \mathrm{MPa}$, for Westerly granite. This figure again shows that the 2DHB failure criterion is, as expected, insensitive to the intermediate principal stress. Again, all criteria, except the GPH, diverge from the common point where $\sigma_{2}^{\prime}=\sigma_{3}^{\prime}=20 \mathrm{MPa}$ and $\sigma_{1}^{\prime}=457.1 \mathrm{MPa}$. Again, the generalised Priest criterion (GP) is the most sensitive to the influence of the intermediate principal stress, predicting substantially higher values of $\sigma_{1}^{\prime}$ than the other criteria and the test data. The simplified Priest criterion (SP), adopting Eq. (13) to calculate the weighting factor $w$, is the least sensitive, with the GZZ again lying between these two. These latter two criteria appear to model the test data 


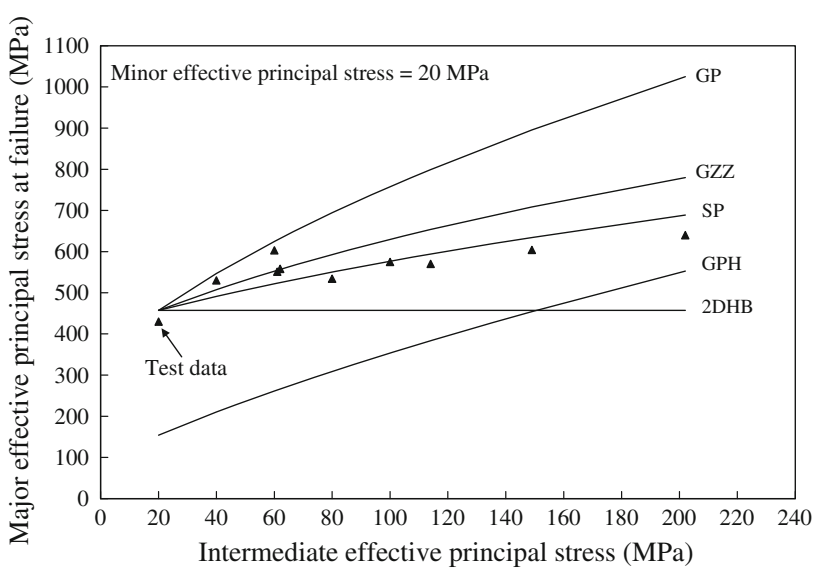

Fig. 2 Four three-dimensional Hoek-Brown failure criteria and also the two-dimensional Hoek-Brown failure criterion for Westerly granite, $m_{\mathrm{i}}=40.5, \sigma_{\mathrm{ci}}=191.0 \mathrm{MPa}$

reasonably well. This same general pattern is repeated for the test data at other values of intermediate principal stress, presented by Haimson and Chang (2000), with the simplified Priest and the GZZ criteria offering the best models for the test data. As for the KTB amphibolite, the test data for Westerly granite indicate that the sensitivity of $\sigma_{1}^{\prime}$ to $\sigma_{2}^{\prime}$ reduces at higher values of $\sigma_{3}^{\prime}$.

\section{Advantages and Limitations}

The generalised Priest criterion seems to overestimate the experimentally determined true triaxial rock strength for KTB amphibolite and Westerly granite by around 10-30 \% for $\sigma_{2}^{\prime}$ in the approximate range $2 \sigma_{3}^{\prime}$ to $4 \sigma_{3}^{\prime}$. This overestimate rises to more than $50 \%$ at higher values of $\sigma_{2}^{\prime}$. Clearly, the generalised Priest criterion (GP) should be used with some caution at this stage, particularly at higher levels of intermediate principal stress.

The simplified Priest criterion (SP), adopting Eq. (13) to calculate the weighting factor $w$, and the GZZ criterion both provide a reasonably good model of the experimentally determined true triaxial rock strength for KTB amphibolite and Westerly granite. The generalised and simplified Priest criteria (GP, SP) do, however, have the benefit of being amenable to direct explicit evaluation and so are more suitable for incorporation into numerical modelling software. The simplified Priest criterion substantially underestimates the experimentally determined true triaxial rock strength for KTB amphibolite and Westerly granite when the minor principal stress is zero. Under these conditions the weighting factor $w$ in Eq. (13) is zero, which creates a negative slope for the graph of $\sigma_{1}^{\prime}$ versus $\sigma_{2}^{\prime}$ for this failure criterion.
None of the criteria examined, with the exception of the simplified Priest criterion, require additional input parameters beyond $\sigma_{2}^{\prime}$ and the parameters required for the $2 \mathrm{DHB}$ criterion. It is, of course, possible to obtain a close fit to almost any experimental data by incorporating additional parameters (or 'fudge factors') into the formulation of a criterion. Adoption of a criterion with one or more additional parameters would necessitate the determination of these parameters for the particular rock type from a series of true triaxial tests. Such testing facilities are not generally available to rock mechanics practitioners, so existing and future three-dimensional Hoek-Brown failure criteria with additional parameters are likely to be of limited practical use.

A potential advantage of three-dimensional failure criteria based on the Hoek-Brown criterion is that, theoretically, it would be possible to adopt values of $m_{\mathrm{b}}, s$ and $a$ that reflect the properties of a fractured rock mass. Consideration of the strength of fractured rock masses is, however, beyond the scope of these suggested methods.

\section{Recommendations}

A significant obstacle to recommending which, if any, of the above three-dimensional Hoek-Brown failure criteria should be applied to rock materials and rock masses is the relative paucity of rock strength test data for specimens loaded under uniaxial, conventional triaxial and true triaxial conditions for a range of rock types.

It is recommended that a substantial amount of further research and rock testing should be conducted before any of the three-dimensional Hoek-Brown failure criteria can be applied with confidence. This testing, which should cover a wide range of rock types and rock strengths, should follow the testing strategy adopted by Chang and Haimson (2000) for the KTB amphibolite and by Haimson and Chang (2000) for Westerly granite, as follows:

(a) A series of conventional uniaxial and triaxial tests should be conducted on intact rock specimens to determine the uniaxial compressive strength and the Hoek-Brown parameter $m_{\mathrm{i}}$ for the rock material, following the relevant ISRM Suggested Methods. It is also recommended that this series of conventional uniaxial and triaxial tests should be repeated in the true triaxial testing apparatus to assess if there is any specimen geometry or testing machine influence on the strength results.

(b) A series of true triaxial tests should be conducted on specimens of the same intact rock, covering a range of minor and intermediate effective principal stresses. If it is assumed that the geological strength index 
(GSI) is 100 for intact rock, it will then be possible to assess the predictions of the published three-dimensional Hoek-Brown failure criteria over a range of rock types and stress levels.

Evaluation of the three-dimensional Hoek-Brown failure criteria for fractured rock masses presents a substantial challenge. The sampling and testing of undisturbed specimens of fractured rock of a size sufficient to represent in situ rock mass conditions presents a significant technical and financial difficulty. Furthermore, true triaxial testing equipment is currently only capable of testing relatively small specimens of intact rock. One promising strategy might be in situ pressuremeter tests in boreholes coupled with testing of recovered core and/or chips and detailed downhole surveys.

\section{References}

Chang C, Haimson BC (2000) True triaxial strength and deformability of the German Continental Deep Drilling Program (KTB) deep hole amphibolite. J Geophys Res 105:18999-19014

Drucker D, Prager W (1952) Soil mechanics and plastic analysis or limit design. Q Appl Math 10:157-169

Haimson BC, Chang C (2000) A new true triaxial cell for testing mechanical properties of rock, and its use to determine rock strength and deformability in Westerly granite. Int J Rock Mech Min Sci 37:285-296

Hoek E, Brown ET (1997) Practical estimates of rock mass strength. Int J Rock Mech Min Sci Geomech Abstr 34:1165-1186

Hoek E, Carranza-Torres S, Corkum B (2002) Hoek-Brown failure criterion-2002 version. Rockscience. http://www.rockscience. com/highlights

Kim MK, Lade PV (1984) Modelling rock strength in three dimensions. Int J Rock Mech Min Sci Geomech Abstr 21:21-33

Melkoumian N, Priest SD, Hunt SP (2009) Further development of the three-dimensional Hoek-Brown yield criterion. Rock Mech Rock Eng 42:835-847

Pan XD, Hudson JA (1988) A simplified three-dimensional HoekBrown yield criterion. In: Romana M (ed) Rock mechanics and power plants. Balkema, Rotterdam, pp 95-103

Priest SD (2005) Determination of shear strength and three-dimensional yield strength for the Hoek-Brown criterion. Rock Mech. Rock Eng 38:299-327

Priest SD (2009) Comparisons between selected three-dimensional yield criteria applied to rock. Rock Mech Rock Eng 43:379-389

Takahashi M, Koide H (1989) Effect of the intermediate principal stress on strength and deformation behavior of sedimentary rocks at the depth shallower than $2000 \mathrm{~m}$. In: Maury V, Fourmaintraux D (eds) Rock at great depth, vol 1. Balkema, Rotterdam, pp 19-26

Zhang L (2008) A generalized three-dimensional Hoek-Brown strength criterion. Rock Mech Rock Eng 41:893-915

Zhang L, Zhu H (2007) Three-dimensional Hoek-Brown strength criterion for rocks. J Geotech Geoenviron Eng ASCE 133:1128-1135 